\title{
Cross-Cultural Factors and Identity in Adolescence
}

\author{
Vanya Matanova and Anna Hristova
}

\subsection{Introduction}

In European countries, multiculturalism is a social reality that has widespread official support. Modern societies are characterized by commitments such as respect for others and celebration of the riches of cultural diversity. However, in practice, these commitments run into difficulties especially when they come into conflict with other priority issues.

In this chapter, the story of "B," a young woman with self-harming behavior, and her family, is presented in six episodes that together illustrate the impact of the values conflicts arising from multiculturalism on early child development and on the establishment of identity in adolescence. B's story further illustrates how cross-cultural psychology highlights cultural values as they arise in therapy.

\subsubsection{Cross-Cultural Psychology and Family Therapy}

Cross-cultural psychology engages with the challenges of multiculturalism by addressing the cultural influences that affect mental processes and behaviors and

\section{Matanova $(\bowtie)$}

Sofia University, Sofia, Bulgaria

Bulgarian Association of Clinical and Counseling Psychology and Bulgarian Association of Dyslexia, Sofia, Bulgaria

"Clinical Psychology in Action" Foundation, Sofia, Bulgaria

Institute of Mental Health and Development, Sofia, Bulgaria
A. Hristova
Institute of Mental Health and Development, Sofia, Bulgaria
(C) The Author(s) 2021
D. Stoyanov et al. (eds.), International Perspectives in Values-Based Mental
Health Practice, https://doi.org/10.1007/978-3-030-47852-0_16 
their impact on individual human behavior in the context of family life, transgenerational relationships, and social experience. It thus supports family therapy and other clinical interventions by helping to make explicit the cultural influences that affect mental processes and behaviors, different cultural patterns, and how they influence human behavior.

In the history of family therapy, tackling cultural differences is an important issue. The roots of this lie in part in the field of anthropology, notably in the work of Gregory Bateson [1] who inspired the first generation of family therapists to use direct observation to describe the patterns and structures underlying family interactions. Against this background, it is natural to ask what we know about Hungarian and British culture, and whether ignorance about significant values and prejudices in them would threaten the counseling and trust relationship in therapy.

In the following narrative, the story of B and her family illustrates the importance of cross-cultural competence in family therapy, involving the ability to understand cultural dynamics within families and across generations and thus react to cultural aspects of a young person's mental health issues in a way that facilitates their development. Further reading on cross-cultural psychology is given in our Guide to Further Sources.

\subsection{Narrative Episode I: B Travels from Britain to Bulgaria}

$B$ was born from a mixed marriage, her mother being from the UK and her father from Bulgaria, that lasted for just a year (in the UK). After her parents divorce, B.'s mother was awarded custody with her father being granted visiting rights, which he followed strictly over the years.

Twelve years later B's parents agreed that she should move to Bulgaria to live with her father. This was because B's mother could not cope with the self-harming behavior that B had developed. It was a recurrence of this that, 8 months after B's arrival in Bulgaria, led her father to seek psychological support.

Consistently with contemporary multiculturalism, B's father had by this time entered into another mixed marriage. His new wife was Hungarian and they now had a son, age 3. During the first meeting, he shared an additional problem-his present wife, being in Bulgaria for 3 years, had made no attempt to study the local language-she lived in isolation, taking care of their child. Yet another factor that came to light was that B.'s father did business all over the world, travelling frequently and for prolonged periods.

$B$ 's father nonetheless declared confidently that there were no difficulties based on cultural differences in his family because everything that went on happened exactly as he said it should, and his wife and others just agreed and complied with his decisions and opinions. This was consistent with his beliefs about family functioning in general, where the man (father and husband) is the leading figure. This authoritarianism was also the basis of his approach to resolving family problems and disagreements. 


\subsubsection{Values Comment: Cultural Values Hidden in Plain Sight}

Note that in B's initial referral, her father was focused solely on her self-harming behavior and made no mention of her new family set up. From a value perspective, the family set up clearly brings the potential for multicultural conflicts straight into focus. $\mathrm{B}$, as a teenager seeking to adapt to a new family, now has to cope with no less than three nationalities and three languages. Yet none of this was mentioned initially by B's father-it was all in effect invisible to him essentially because it reflected local cultural values that being deeply embedded he simply took them for granted as "normal."

We see similar "values hidden in plain sight" later in this part of B's story in her father's confident denial of any difficulties arising from cultural differences. B's father was not being disingenuous. He was simply unaware of any such difficulties because, reflecting traditional Bulgarian values of the "strong father," he had asserted his control as he saw it effectively. We return to this "strong father" cultural value in later parts of B's story.

\subsection{Narrative Episode II: Parenting Styles}

B's father described her first self-harming injuries in Bulgaria as "scratches" made with a razor blade in the area of her forearm (between the elbow and the wrist) away from the veins, i.e. without being life-threatening.

$B$ had started self-harming 2 years earlier while she was still living with her mother. At this time B was often alone: her mother worked in shifts, also living away to care for a sick grandma and her two dogs. The control she exercised over the B's life was thus weak and chaotic. She tried to compensate for her absence by taking over all the household chores at home, excluding B from them. Thus, overwhelmed by everyday tasks, B's mother hardly ever found time to spend with her daughter.

By contrast, in her new Bulgarian family, B encountered strong authoritarian control exercised by her father, which she described as a "strangle-hold". She was accompanied everywhere, and her requests to be left alone remained unheeded. So, from an overly indulgent parenting style with inconsistent control, B now found herself with an authoritarian father who exercised overly strict control.

The consultations with B's father significantly lowered his parental anxiety about $B$ 's self-injury. With greater confidence, he succeeded in letting $B$ have time alone out of their home. To ensure B felt part of the daily life of her new family, he allowed her to make her own choices and included her in certain domestic activities and responsibilities.

\subsubsection{Values Comment: Cultural Values and Parenting Styles}

In recent years, there has been a visible increase in the prevalence of self-harm in the non-clinical adolescent population in general [2]. Causal factors vary but the 
style of parenting attributed to B's mother is commonly seen in the families of selfharming teenagers - the child feels rejected by the parent and experiences an ambivalent approach to control, which leads to a chaotic and non-transparent family situation [3].

The inconsistent parenting style adopted by B's mother was driven by internal conflicts of values. On the one side, she was concerned about her own mother and (as became clear later) she was also trying to establish herself in a new career. These were among her values; they were things that mattered or were important to her. But also important to her, on the other hand, was her daughter, B. Hence, caught in a conflict of values, she responded in an inconsistent way that left B feeling neglected and insignificant-as she put it: "the very last in line, even after the dogs."

After moving to Bulgaria B found herself subject to the very different values of her father as reflected in his authoritarian style of parenting. As described further below, his values reflect traditional Bulgarian cultural values reinforced by his own family background. But the effect was the opposite of what he had intended in that B's self-harming behavior reappeared. In therapy, helping him to understand the origins of his values, and their unintended consequences on B, allowed him to draw back and let B escape what she experienced as his "strangle-hold".

\subsection{Narrative Episode III: B in Bulgaria}

The radical change that took place in B's life at this stage of her development was a serious challenge. Her father was trying to understand that B was going through a difficult period but he could not accept the way she had chosen to cope with her experiences. At one point, frustrated by his absolute inability to understand the reasons behind B's behavior, he said: 'This isn't what we do!' By 'we', he referred to himself and his kin; so, without realizing it, he had sent a message to his daughter, which, in the process of identification, could be perceived as: "You're not like us.”

\subsubsection{Values Comment: The Good Bulgarian Father}

This may seem a harsh message. But during the sessions with B's father, it became clear that he represented that aspect of traditional Bulgarian culture where the children are a core priority and value for the parents for the rest of their lives, and the family operates with clearly defined family roles.

This type of family culture necessarily implies clear value expectations: it involves setting aside personal time, interests, ambitions, and right to personal life and liberty. In traditional Bulgarian culture, these expectations are directed 
primarily toward the mother. In B's previous family, however, they were not directed to her biological mother. B's father claimed that her mother, "while chasing her career dreams, did not devote enough time to their child." He found it unacceptable for a mother to have priorities other than her children and perceived her ambitions and professional commitment as "a desire to compete with him." All this not only contributed to their separation but his reproaches and accusations toward B's mother continued after their separation.

Because of his business, B's father often had formal and informal contacts with people from different cultures, requiring flexibility and a respectful attitude towards diversity. There had thus been significant opportunities for his ideas and concepts about good motherhood to evolve over time. However, his ideal of 'the good mother' remained essentially unchanged.

Believing he was doing the best for his child, B's father tried to convey his idea of 'the good mother' to her by never missing an opportunity to express in front of her his dissatisfaction with her biological mother.

\subsubsection{Values Comment: The Good Bulgarian Mother}

The explanation for B's father's rather extreme model of the "good mother" lies beyond the framework of his traditional culture and is to be found rather in the dynamics of his own parental family.

His parents were divorced. His mother was granted full custody of their children, and the image of their father was manipulatively demonized. As a result, he and his brothers had no contact with their father for the rest of his life. His mother devoted herself completely to her function as a parent: she deprived herself of her own life, interests, and career; she sacrificed all her time for her family and home and dedicated herself to the role of "mother-heroine," which filled her son (B's father) with loyalty, uncritical trust, and admiration.

\subsection{Narrative Episode IV: B Stays with Her Grandmother}

During the first session of therapy, B had already left her father's home and moved to her paternal grandmother's house. B had declared her desire to make this move in order to master the local language. Her father had agreed with this, because he found it acceptable for a grandmother to raise her granddaughter-this corresponded with their traditional stereotypes and beliefs. However, he was confused: initially, he was confident that language adaptation was the real reason for $B$ wanting to leave his home, but subsequently he started experiencing some hesitation and anxiety.

In the event B's stay with her grandmother did not go smoothly. A series of transgenerational conflicts followed over issues such as daily chores, going out, 
and even the way $B$ dressed. Her father was constantly involved as an arbitrator, which was exhausting for him-he had already started a new job and had no opportunity to answer their constant phone calls or to meet and talk to both of them, together or in private. At this stage, B decided to move back in with her father.

\subsubsection{Values Comment: Cultural Values Across the Generations}

Important to the cultural context of B's story is the strictly hierarchical structure of a traditional Bulgarian family. This is partly a matter of age, partly of gender. In this hierarchical model, the world of men and the world of women are clearly distinguished. The male is dominant (the proper, the good, the right), and the female is the weak (the wrong, the left). The man represents the family before the authorities and in the community; the woman gives birth and cares for the children and the sick. After marriage, the woman enters the new family, loses her name, and takes her husband's [4].

This speaks to the question why B's father failed to mention the different nationalities of his family members in the initial referral (noted above). The problems arising from the multicultural interactions in his family were invisible to him. Being a responsible leader of his family, he did not allow other members to take part in the family sessions. It also explains the transgenerational conflicts between B and her grandmother. B's father had experienced an upbringing that strongly reflected his Bulgarian norms of family life. B, however, did not share these norms.

\subsection{Narrative Episode V: Developing Awareness of Values}

$B$ 's father now realized for the first time that his immense confidence in his motherin his mind the exemplar "good mother"-had misled him. He understood that B's decision to move back in with him was inspired by his mother-he called this " $a$ coalition behind my back." A "secret coalition" in the family means continuous behavior of two of its members from different hierarchical levels (in this case, grandmother and granddaughter), with the purpose of mutual support, although one of the members (the grandmother in this instance) always demonstrates a certain negative emotional attitude towards the other.

This coalition prompted B's father to put up boundaries for the first time between his mother and his family-he stopped sharing with her his emotional disappointments and anxieties and started seeking support from his Hungarian wife. With the increasing role of B in the family, B's father gained confidence and was inclined to give her a degree of autonomy. 


\subsubsection{Values Comment: Balancing Values}

Up to this point as we have seen, B's father idolized his own mother. Now he faced the reality that she was not perfect. This more balanced understanding, as one of the keys to values-based practice (see introductory chapter), allowed him to begin to move forward in therapy.

\subsection{Narrative Episode VI: Crisis as a Starting Point}

Realizing the problem of adaptation, B's father made a solo decision and without any prior discussion, sent his second wife to a Bulgarian language course and registered their young son in a local Bulgarian pre-school.

As to B, when she arrived In Bulgaria, she was enrolled in a private English school attended by local children as well as by children of a different background. The latter, however, belonged to a particular ethnicity and formed a single 'in crowd' group. B did not identify with any of the various school communities and failed to develop close friendships. She tried only once to make friends with one of her classmates. They did not get in touch at school but she received invitations to religious gatherings of a community to which her classmate belonged. B's father felt particularly anxious about this friendship and kept himself closely informed of any details about their meetings outside school. B never managed to fit into her peer group. For a short time she joined a Facebook group of English people living in Bulgaria.

Disappointment and difficulties in B's adaptation to Bulgaria, as well as nostalgia about her English friends, ended in B wanting to return to Britain. Her mother was supportive, but her father was against another change. After talking with him about this, B's psycho-emotional state deteriorated.

\subsubsection{Values Comment: Crisis as Both a Values Challenge and a Values Opportunity}

The strict hierarchy in B's new family was now in crisis. With her father, who as we have seen was a dominating authority, now traveling frequently and being absent from home for extended periods, and with his Hungarian wife (her surrogate mother) adapting more slowly than B to cultural transitions and thus unable to perform her parental role adequately, B faced additional instabilities.

These instabilities, arising as in this story from conflicting cultural values, have the consequence that intra-family tensions between a parent and a teenager can be significantly aggravated. Clearly, there was more work to do. But with the relevant values now finally becoming visible to those concerned, the cultural context of family functioning became an effective starting point for family therapy [5]. 


\subsection{Conclusions}

"Identity vs. diffusion" according to Erikson [6] is the time when adolescents actively try to synthesize their experience and to form a stable sense of personal identity. Identity development is formed not only from the psychosocial point of view, but also from the ethnic point of view. Root's model [7] is one of the first to go beyond the paradigm of identity deficit when considering the development of personality in individuals of mixed origin. Adolescents of mixed ethnicity have more than one choice for healthy identification. Root believes that internal conflicts related to the identification of mixed-ethnicity adolescents are due to political, social, or family processes.

The importance of these insights is evident in the story of B and her family. Reading the story as we have set it out here through a values lens informs effective family therapy interventions in the context of the challenges of contemporary multiculturalism.

\subsection{Guide to Further Sources}

For further information on cross-cultural psychology please see:

1. Henriksen Jr., R. C., \& Paladino, D. A. (2009). Identity development in a multiple heritage world.

2. La Roche, M. J., \& Maxie, A. (2003). Ten considerations in addressing cultural differences in psychotherapy. Professional Psychology: Research and Practice, 34 (2), 180.

3. Romero, D. (1985). Cross-cultural counseling: Brief reactions for the practitioner. The Counseling Psychologist, 13 (4), 665-671.

4. Sue, D. W., Sue, D., Neville, H. A., \& Smith, L. (2019). Counseling the culturally diverse: Theory and practice. John Wiley \& Sons.

\section{References}

1. Bateson G. Steps to an ecology of mind: collected essays in anthropology. Psychiatr Evol Epistemol. 1972;381.

2. Lloyd-Richardson EE, Perrine N, Dierker L, Kelley ML. Characteristics and functions of nonsuicidal self-injury in a community sample of adolescents. Psychol Med. 2007;37(8):1183-92.

3. Burešová I, Bartošová $\mathrm{K}$, Čerňák $\mathrm{M}$. Connection between parenting styles and self-harm in adolescence. Procedia Soc Behav Sci. 2015;171:1106-13.

4. Gavrilova B. "Bŭlgarskoto patriarhalno semeřstvo: Vlast, zakon, ı̌erarkhiya", dots. Anna Luleva, dots. Aneliya Kasabova, gl. as. Mariya Markova, Institut za etnologiyaifolkloristika s etnografskimuzeř pri BAN, dots.TanyaBoneva, SU, dots.MariyaKitanovaotInstituta za bylgarskiezik, radioentsiklopediya; 2015. 
5. Repetto E. Cross-cultural counseling: problems and prospects. Orientación y Sociedad. 2002;3:29-35.

6. Erikson EH, editor. Youth: change and challenge. New York: Basic books; 1963.

7. Root MPP. Resolving 'other' status: identity development of biracial individuals. Women Ther. 1990;9:185-205.

Open Access This chapter is licensed under the terms of the Creative Commons Attribution 4.0 International License (http://creativecommons.org/licenses/by/4.0/), which permits use, sharing, adaptation, distribution and reproduction in any medium or format, as long as you give appropriate credit to the original author(s) and the source, provide a link to the Creative Commons license and indicate if changes were made.

The images or other third party material in this chapter are included in the chapter's Creative Commons license, unless indicated otherwise in a credit line to the material. If material is not included in the chapter's Creative Commons license and your intended use is not permitted by statutory regulation or exceeds the permitted use, you will need to obtain permission directly from the copyright holder. 